\title{
Exogenous application of salicylic acid influences fruit softening and quality of 'flordaking' peach during ripening at ambient conditions
}

\author{
Sami Ullah ${ }^{1 *}$, Ahmad Sattar Khan ${ }^{2}$, Aman Ullah Malik ${ }^{2}$, Kashif \\ Razzaq $^{1}$, Muhammad Amin ${ }^{1}$, Gulzar Akhtar ${ }^{1}$ and Hafiz Nazar Faried ${ }^{1}$ \\ 1. Department of Horticulture, MNS-University of Agriculture, Multan-Pakistan \\ 2. Institute of Horticultural Sciences, University of Agriculture, Faisalabad-Pakistan \\ *Corresponding author's email: sami.ullah1@mnsuam.edu.pk
}

Citation

Sami Ullah, Ahmad Sattar Khan, Aman Ullah Malik, Kashif Razzaq, Muhammad Amin, Gulzar Akhtar and Hafiz Nazar Faried. Exogenous application of salicylic acid influences fruit softening and quality of 'flordaking' peach during ripening at ambient conditions. Pure and Applied Biology. Vol. 9, Issue 1, pp1009-1024.

http://dx.doi.org/10.19045/bspab.2020.90106

Received: 14/10/2019 Revised: 31/12/2019

Accepted: 03/01/2020

Online First: 18/01/2020

\section{Abstract}

Effects of postharvest application of salicylic acid (SA) on ethylene production, fruit softening and quality of peach fruit (Prunus persica L. Batsch, cv 'Flordaking') were investigated during fruit ripening at ambient conditions $\left(25 \pm 2{ }^{\circ} \mathrm{C}\right.$ and $\left.60-65 \% \mathrm{RH}\right)$. Peach fruit treated with aqueous solutions of different concentrations of SA $(0,2,4$ or $6 \mathrm{mM})$ were analyzed for fruit softening and fruit quality attributes. Results revealed that peach fruit treated with 4- and 6-m $M$ SA exhibited delayed and reduced ethylene production as compared to untreated fruit during fruit ripening. Reduced activities of fruit softening enzymes including pectin esterase (PE), endo-1-4 $\beta$ Glucanase (EGase), endo- and exo-polygalacturonase (endo-PG and exo-PG) were observed in 6$\mathrm{m} M$ SA-treated fruit, as compared to untreated fruit during ripening at ambient conditions. Peach fruit treated with 6-m $M$ SA exhibited the lowest fruit weight loss, soluble solid contents (SSC); while, highest fruit firmness than untreated fruit during ripening at ambient conditions. Moreover, application of 6-m $M$ SA significantly enhanced the antioxidant scavenging activity (ASA), total phenolic contents (TPC) and activities of antioxidative enzymes including catalase (CAT), peroxidase (POD) and superoxide dismutase (SOD) enzymes as compared to untreated peach fruit during ripening. Conclusively, application of 6-m $M$ SA significantly reduced ethylene production, fruit flesh softening, activities of fruit softening enzymes and increased activities of anti-oxidative enzymes of peach fruit during ripening at ambient conditions.

Keywords: Ethylene; Fruit softening enzymes; Prunus persica L.; Shelf-life; Soluble solid contents; Total phenolic contents

\section{Introduction}

Peach is an important stone fruit crop grown in the temperate, Mediterranean and subtropical climates of the world. The world production of peach fruit is about 21.53 million tons that making it the third largest 
species of fruit tree in terms of production in the world. Among leading peach producing countries, China ranks $1 \mathrm{st}$ in production with $53.6 \%$ share in the world followed by Italy and Spain. Whereas, Pakistan shares only about $1 \%$ of the world peach production [1]. Peaches are very perishable fruit in nature. Being climacteric fruit, they ripe very quickly at ambient conditions [2]. Rapid postharvest fruit softening and quality deterioration reduce shelf life of peach fruit at room temperature. However, high enzymatically regulated cell wall degradation lead to extensive fruit softening during prolong low temp storage [3]. Peach fruit softening involves enzymatic modifications of the pectin molecules associated with changes in cell wall composition and structure [3]. Pectin esterase (PE; EC 3.1.1.15), endo $(1,4)$ $\beta$-glucanase (EGase; EC 3.2.1.4), endopolygalacturonase (endo-PG; EC 3.2.1.15) and exo-polygalacturonase (exo-PG; EC 3.2.1.67) have been reported as key cell wall hydrolyzing enzymes in peach fruit [4]. Moreover, it has been reported that peach fruit experience postharvest quality deterioration due to the imbalance between the amount of reactive oxygen species (ROS) produced and ROS scavenging capacity, resulting in enhanced lipid peroxidation and membrane injury [5, 6]. Excessive production of ROS results in loss of compartmentalization of fruit between enzymes and their substrates resulting in enzymatic browning [7]. Therefore, application of postharvest handling techniques to delay fruit softening and inhibit ROS production are important for reducing quality deterioration and extending the postharvest storage life of peach fruit.

Salicylic acid (SA) is an aromatic compound belonging to an extremely diverse group of plant phenolics. It is well documented that $\mathrm{SA}$ is involved in various physiological and biochemical processes of plants including, photosynthesis, ion uptake, membrane permeability, enzyme activities, growth and development [8]. Postharvest application of SA has been reported to delay ripening in various fruits including banana [9], strawberry [10], pear [11], peach [12], and sweet pepper [13]. Application of SA as postharvest dips treatments had been reported to inhibit ethylene biosynthesis and action in banana and pear fruits, respectively $[9,14]$. Moreover, postharvest application of SA revealed a reduction in melonidialdehyde content, activities cell wall degrading enzymes (EGase, PG and xylanase) and increased level of reducing sugars, flavonoids, DPPH scavenging activity in many fruits including banana [9], strawberry [10], cactus pear [15] and kiwifruit [16]. The potential of postharvest application of SA alone or in combination with antagonistic yeast have been reported to control postharvest diseases in strawberry [17], persimmon [18], apple [19], sweet cherry [20] and peach [21, 22]. Postharvest application of SA has also been found to alleviate the chilling injury in mango [23], cactus pear fruit [15], peach [12, 24], loquat [25] and pomegranate [26].

Although, postharvest application of SA on peach fruit has been reported [12, 24, 27], however, focus of earlier studies of SA on peach was on management of postharvest decay, chilling injury, conventional fruit quality parameters like SSC: TA ratio, organic acid or sugars along with activities of antioxidative enzymes. To the best of our knowledge, effect of SA on activities of fruit softening enzymes has not been studied. Therefore, we hypothesized that postharvest application of SA will reduce activities of fruit softening and quality enzymes. Hence, a study was planned to investigate the role of postharvest application of SA in regulation of activities of fruit softening enzymes (PE, EGase, endo-PG and exo-PG) and antioxidative enzymes (CAT, POD and SOD) in 
pulp tissues of 'Flordaking' peach during fruit ripening.

\section{Materials and methods}

\section{Fruit source}

Five years old healthy peach (Prunus persica L. Batsch) cv. 'Flordaking' trees of uniform size, grafted on peach seedling rootstock trained on a central open leader system were selected for study at Horticulture Research Station, Noshehra, Soan Valley Distt. Khushab. Uniform sized fruit, free from diseases and visual blemish symptoms were harvested at physiological mature stage (firmness $74 \pm 1.1 \mathrm{~N}$, SSC $7.0 \pm 0.5^{\circ} \mathrm{Brix}$ ) and transported to Postharvest Research and Training Centre, Institute of Horticultural Sciences, University of Agriculture Faisalabad, Pakistan in an air forced temperature controlled reefer van.

\section{Experimental treatments}

Harvested peach fruit were divided into 4 equal lots for the application of different treatments. Postharvest SA treatments were carried out by immersing the peach fruit in aqueous solutions of 0 (control), 2, 4 or $6 \mathrm{mM}$ $\mathrm{SA}$ for $5 \mathrm{~min}$ at room temperature with $0.01 \%$ Tween $20^{\circledR}$ as surfactant. SA-treated fruit were allowed to ripe at ambient conditions at $25 \pm 2^{\circ} \mathrm{C}$ and $60-65 \% \mathrm{RH}$. Data regarding peach fruit physiological attributes (respiration rate and ethylene production), fruit quality parameters (fruit weight loss, firmness, colour, SSC, TA, TPC, ASA) and activities of various enzymes (fruit softening and anti-oxidative) were recorded during ripening for 4-days. Ten fruit were used as an experimental unit. The experiment was conducted using CRD under factorial arrangement replicated three times.

\section{Ethylene production and respiration rate}

For determination of ethylene production and respiration rate, two peach fruit per experimental unit were put in an air tight plastic jar having $2200 \mathrm{~mL}$ volume. A hand held ethylene analyzer (Model-56, ICA Storage Limited, UK) was used to determine ethylene production; while, respiration rate was determined by using hand held $\mathrm{CO}_{2}$ gas analyzer (Model MI-70, Vaisala, Finland) at room temperature. Ethylene production and respiration rate were expressed as $\mu \mathrm{L} \mathrm{C}_{2} \mathrm{H}_{4}$ $\mathrm{kg}^{-1} \mathrm{~h}^{-1}$ and $\mathrm{mL} \mathrm{CO} \mathrm{kg}^{-1} \mathrm{~h}^{-1}$ of fresh fruit weight, respectively.

\section{Physical fruit quality}

Fruit weight loss was measured and was expressed as percentage of fruit weight. Firmness of peach fruit was measured with a penetrometer (Model DFM50, Ametek Inc., USA) fitted with $8 \mathrm{~mm}$ tip. It was expressed in Newton (N). Ground colour of peach was determined subjectively by using a scale based on visual observations from 1 (25\% yellow and $75 \%$ green) to 4 (100\% yellow and $0 \%$ green) as reported by Ullah et al. [28].

\section{Activities of fruit softening enzymes}

The activities of fruit softening enzymes including pectin esterase (PE; EC 3.1.1.11), EGase (EC 3.1.1.4), endo-PG (EC 3.2.1.67) and exo-PG (EC 3.2.1.15) from peach fruit pulp tissues were determined by using the method as reported by Khan and Singh [29]. Protein contents of peach fruit were determined by using Bradford reagent and were expressed as $\mathrm{mg} \mathrm{g}^{-1}$ of fruit weight. Bovine serum albumin was used as standard for determination of protein contents. Activity of PE was determined by titrating the reaction mixture containing citrus pectin as substrate against $0.01 \mathrm{~N} \mathrm{NaOH}$ at $30^{\circ} \mathrm{C}$. $\mathrm{PE}$ activity was expressed as $\mathrm{m} M \mathrm{NaOH}$ used $\mathrm{mg}^{-1}$ protein $\mathrm{h}^{-1}$. For EGase activity, enzyme reaction mixture containing carboxymethyl cellulose as substrate was incubated for $18 \mathrm{~h}$ at $30^{\circ} \mathrm{C}$. EGase activity was expressed as $\Delta$ viscosity $\mathrm{mg}$ protein ${ }^{-1} \mathrm{~h}^{-1}$. The activity of endo-PG was also measured by CanonFenske Routine Viscometer as described in EGase determination, using polygalacturonic acid as substrate in reaction mixture and was expressed as $\Delta$ viscosity $m g$ protein ${ }^{-1} \mathrm{~h}^{-1}$. The activity of exo-PG was determined by 
measuring cyanoacetamide released reducing group from substrate poygalacturonic acid with the help of UV-VIS spectrophotometer (UV-1800, Shimadzu Corp., Kyoto, Japan) at $274 \mathrm{~nm}$. It was expressed as $\mu \mathrm{g}$ galacturonic acid $m g$ protein ${ }^{-1} \mathrm{~h}^{-1}$.

\section{Biochemical fruit quality}

SSC of peach fruit juice was recorded with a hand held digital refractometer (Model RX 5000 Atago, Japan) and was expressed as ${ }^{\circ}$ Brix. TA of peach juice was determined by titration with $0.1 \mathrm{~N} \mathrm{NaOH}$ to light pink end point, using phenolphthalein as an indicator and expressed as \% malic acid. The level of ascorbic acid was determined by the protocol of Ullah et al. [28] and was expressed as mg $100 \mathrm{~g}^{-1}$.

Total phenolic contents and antioxidants scavenging activity

Total phenolic contents (TPC) from peach fruit pulp were determined by the method of Ullah et al. [28] using Folin-Ciocalteu (FC) reagent. TPC was express as mg GAE $100 \mathrm{~g}^{-}$ ${ }^{1}$ (gallic acid equivalent) by using gallic acid as standard. Antioxidant scavenging activity was measured and antioxidant scavenging activity was determined as percentage inhibition.

\section{Activities of antioxidative enzymes}

The activities of catalase (CAT; EC 1.11.1.6) and peroxidase (POD; EC 1.11.1.7) and superoxide dismutase (SOD; EC 1.15.1.1) enzymes were determined by using method of Ullah et al. [28]. Activities of CAT and POD was expressed as $\mathrm{U}$ mg protein ${ }^{-1}$, where one unit was defined as "an absorbance change in 0.01 unit $\mathrm{min}^{-1}$ ". The activity of SOD was expressed as U mg protein ${ }^{-1}$, where one unit was defined as "the quantity of enzyme used to inhibit $50 \%$ photoreduction of NBT".

\section{Statistical analysis}

The experimental data were analyzed with two way ANOVA (treatments and days at ripening as factors) under $\mathrm{CRD}$ factorial arrangement using Statistix $10^{\circledR}$ (Analytical Software, Tallahasee, FL, USA) for windows software. LSD test $(P \leq 0.05)$ was employed to test the significance of experimental means. Pearson's correlations were also performed to estimate relationship between fruit firmness and activities of fruit softening and antioxidative enzymes using Statistix $10^{\circledR}$.

\section{Results}

Ethylene production and respiration rate Ethylene production increased in both SAtreated and untreated peach fruit during ripening (Fig. 1A). Application of different concentrations of SA delayed the climacteric ethylene peak by two days, as compared to untreated fruit. On an average, peach fruit treated with SA exhibited reduced ethylene production, as compared to untreated fruit (Fig. 1A). This reduction was more pronounced at higher concentrations of SA. On day- 6 of ripening, peach fruit treated with $6 \mathrm{~m} M$ SA revealed about 1.32-fold less ethylene production than untreated fruit.

Similarly, both SA-treated and untreated peach fruit showed an increased respiration rate during fruit ripening (Fig. 1B). Untreated fruit exhibited respiration peak on day-3 of fruit ripening; however, SA-treated fruit showed no peak for respiration. Significant suppressed respiration rate was observed in peach fruit treated with different concentration of SA, as compared to untreated fruit. This suppression was more pronounced in fruit treated with higher concentration of SA, as compared to other chemicals. On day- 6 of fruit ripening, peach fruit treated with $6 \mathrm{~m} M \mathrm{SA}$ showed about 1.24-fold less respiration rate, as compared to untreated fruit. 


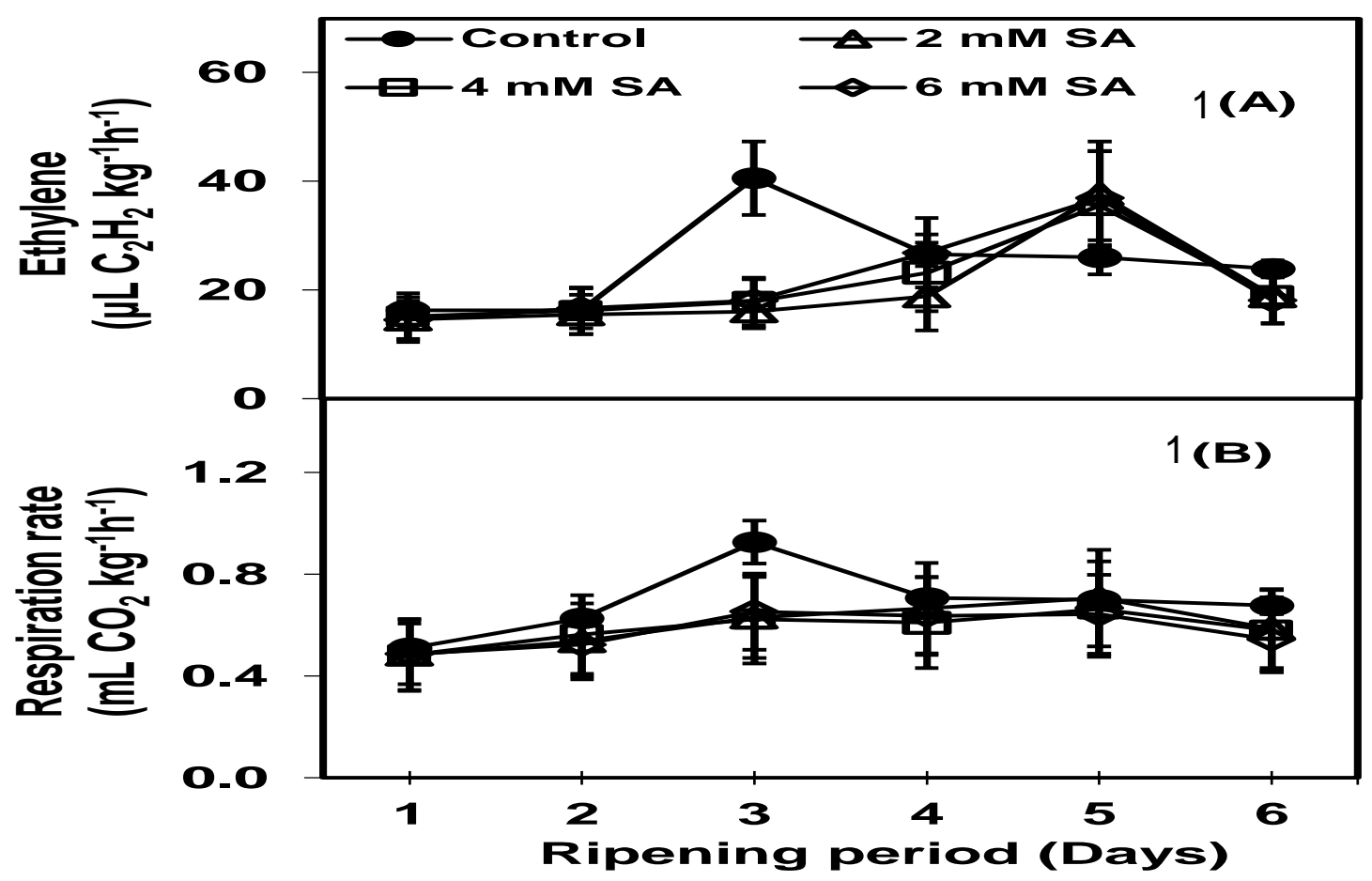

Figure 1. Effect of exogenous application of salicylic acid (T) on ethylene production (A) and respiration rate $(B)$ of 'Flordaking' peach fruit during ripening (RP). Vertical bars denotes SE of means. $n=3$, LSD values (NS, *, ** indicates non-significant, significant at $P \leq 0.05$ and significant at $P \leq 0.01$, respectively). ethylene: $\mathrm{T}=1.44 * *, \mathrm{RP}=1.44 * *, \mathrm{~T} \times \mathrm{RP}=3.22^{* *}$, respiration rate; $\mathbf{T}=0.023 * *, \mathbf{R P}=0.023^{* *}, \mathbf{T} \times \mathbf{R P}=0.056 * *$.

Fruit weight loss, ground colour and fruit firmness

Fruit weight loss showed significant increasing trend during ripening, irrespective to treatments (Fig. 2A). Application of different concentration of SA significantly reduced the weight loss, as compared to untreated fruit. Reduction in fruit weight loss was more pronounced in fruit treated with higher concentrations of SA. On day-4 of fruit ripening, peach fruit treated with $6 \mathrm{mM}$ SA exhibited about 2.38-fold less fruit weight loss, as compared to untreated fruit.

During ripening, peach fruit developed an increased ground colour, irrespective to treatments (Fig. 2B). Application of SA delayed the ground colour development in a concentration dependent manner and the least colour development (2.32-fold) was exhibited the peach fruit treated with $6 \mathrm{mM}$
SA on day-4 of ripening in contrast to control fruit.

During ripening, fruit firmness significantly decreased in both SA-treated and untreated fruit (Fig. 2C). However, application of SA slowed down decline in peach fruit firmness, as compared to untreated fruit. Peach fruit treated with higher concentrations of SA exhibited the most delayed loss of fruit firmness than other concentrations. On day-4 of ripening, fruit treated with $6 \mathrm{~m} M \mathrm{SA}$ showed about 2.55-fold less decline in firmness, as compared to untreated fruit.

Activities of fruit softening enzymes

Significant increased activities of pectin esterase (PE) enzymes in both SA-treated peach fruit and untreated peach fruit were observed during ripening (Fig. 3A). Postharvest application of SA significantly reduced the activities of $\mathrm{PE}$ enzymes, as 
compared to untreated fruit. This reduction was more pronounced in fruit treated with higher concentration of SA, as compared to other concentrations applied. On day-4 of ripening, the lowest PE activity was observed in peach fruit treated with $6 \mathrm{~m} M \mathrm{SA}$, about 1.8-fold lower activity, as compared to untreated fruit.

Activities of EGase enzymes also showed a significant increasing pattern in peach fruit during ripening, irrespective to treatments (Fig. 3B). Significant lower activities of EGase enzymes were observed in SA-treated peach fruit as compared to untreated fruit.
Peach fruit treated with6 $\mathrm{m} M$ SA exhibited about 1.6-fold less activities of EGase enzymes in contrast to control fruit on day-4 of ripening.

Application of SA markedly reduced the endo-polygalacturonase (endo-PG) enzymes activities in peach fruit during ripening (Fig. 3C). Peach fruit treated with higher concentration of SA exhibited the lowest endo-PG enzymes activities than other treatments. Peach fruit treated with $6 \mathrm{~m} M \mathrm{SA}$ showed about 1.96-fold less endo-PG enzymes activities as compared to untreated fruit on day-4 of ripening.

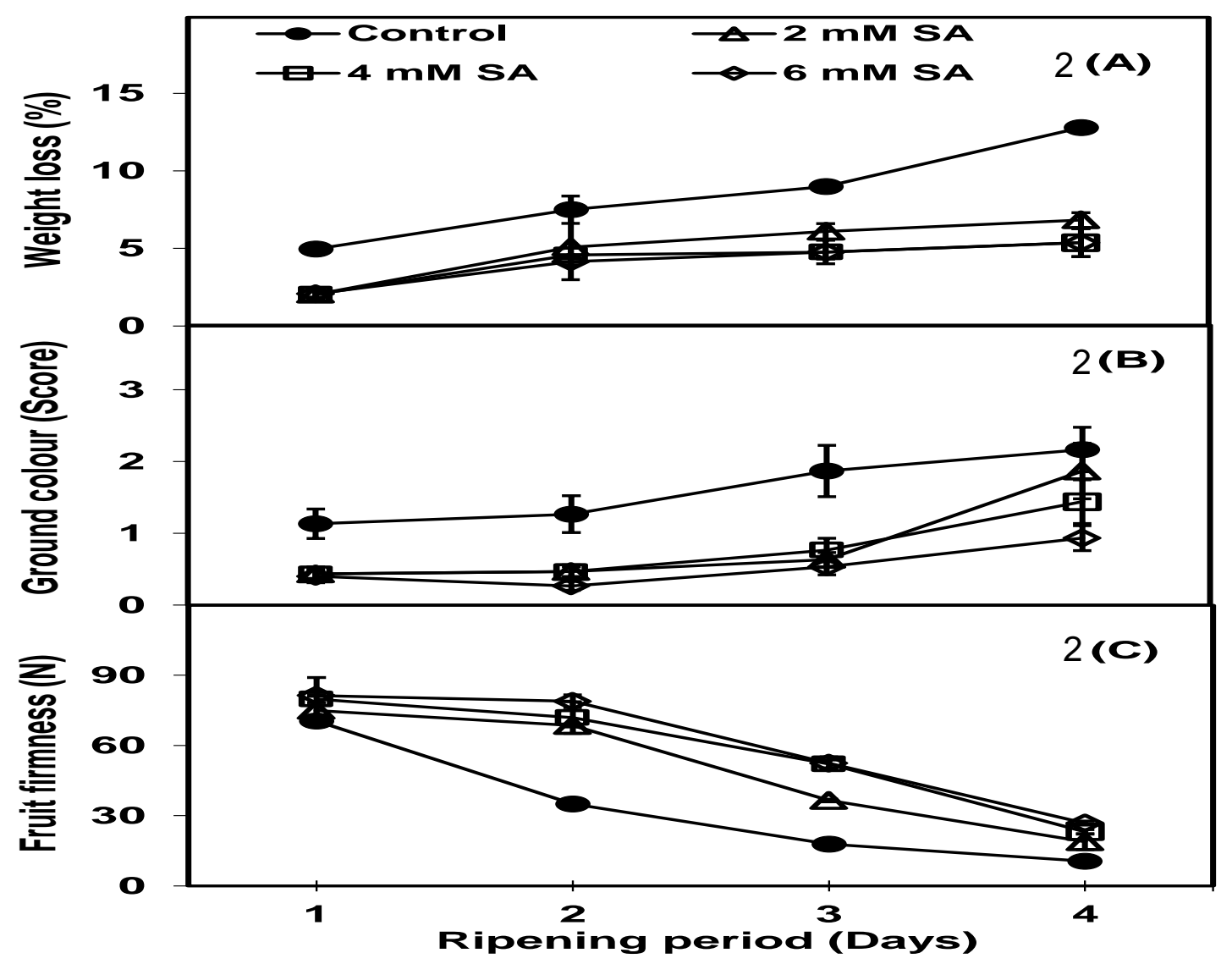

Figure 2. Effect of exogenous application of salicylic acid (T) on fruit weight loss (A), fruit ground colour (B) and fruit firmness (C) of 'Flordaking' peach during ripening. Vertical bars denotes SE of means. $n=3$, LSD values $(\mathrm{NS}, *$, ** indicates non-significant, significant at $P \leq 0.05$ and significant at $P \leq 0.01$, respectively). weight loss: $T=0.816^{* *}, R P=0.816 * *$, $\mathbf{T} \times \mathbf{R P}=1.632 * *$; ground colour $: \mathbf{T}=0.132 * *, \mathbf{R P}=0.132 * *, \mathbf{T} \times \mathbf{R P}=0.281 *$; fruit firmness $: \mathbf{T}=2.323^{*} *, \mathbf{R P}=2.323^{* *}, \mathbf{T} \times \mathbf{R P}=5.194 * *$ 
Similarly activities of exo-polygalacturonase (exo-PG) enzymes in both SA-treated and untreated peach fruit exhibited an increasing trend during ripening (Fig. 3D). However, application of SA significantly reduced the exo-PG enzyme activity, as compared to untreated peach fruit. The reduction was more pronounced at in fruit treated with higher concentration of SA, as compared to other concentrations. The least activities of exo-PG enzymes were found in $6 \mathrm{~m} M \mathrm{SA}$ treated peach fruit, (about 1.57-fold less than untreated fruit) on day-4 of ripening.

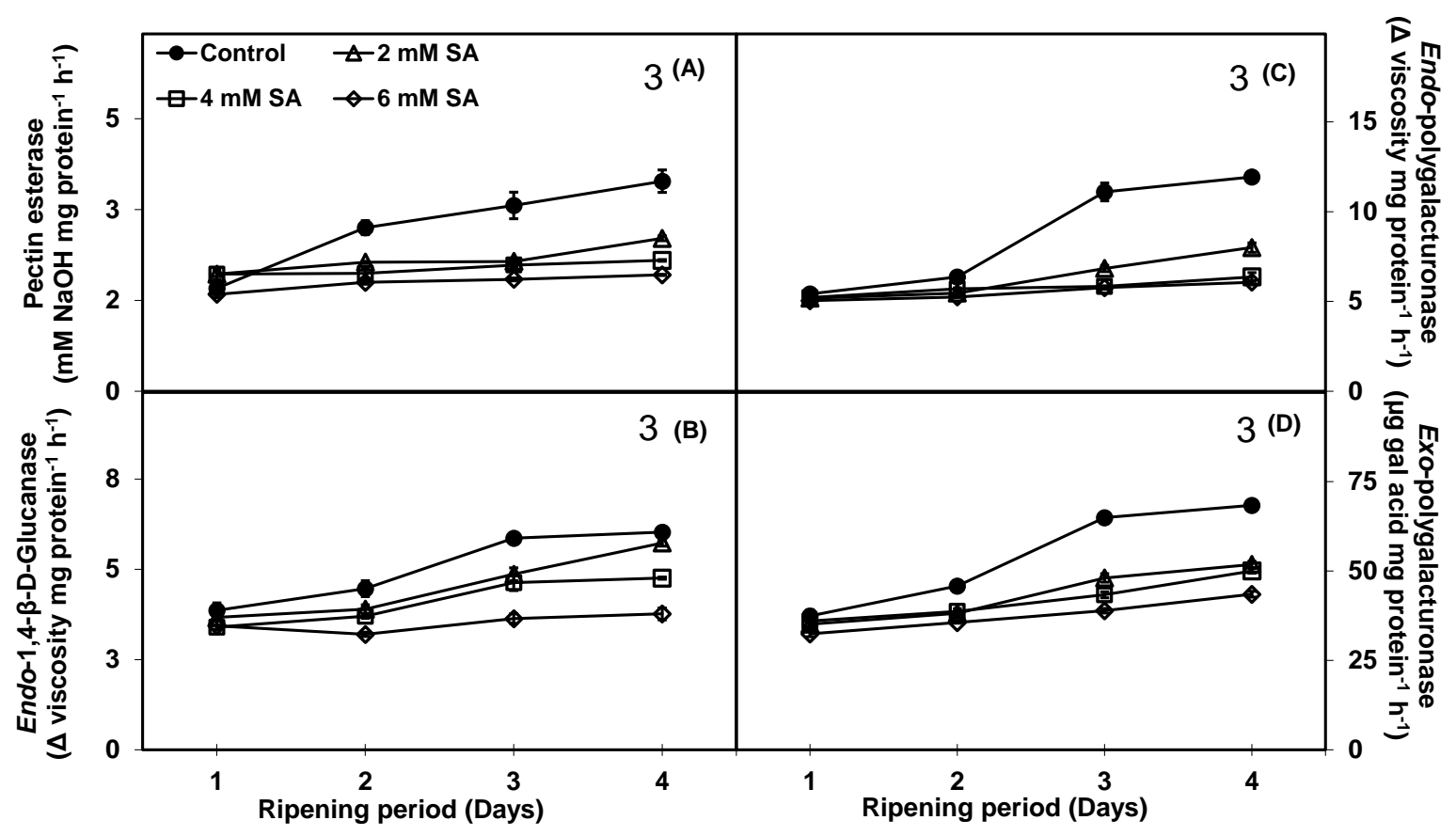

Figure 3. Effect of exogenous application of salicylic acid (T) on activities of pectin esterase (A), endo-1,4- $\beta$-D glucanase (B), endo-polygalacturonase (C) and exo-polygalacturonase (D) enzymes in pulp tissues of 'Flordaking' peach during ripening (RP). Vertical bars denotes $\mathrm{SE}$ of means. $\mathrm{n}=3$. LSD values $(\mathrm{NS}, *$, ** indicates non-significant, significant at $P \leq \mathbf{0 . 0 5}$ and significant at $P \leq 0.01$, respectively). pectin esterase: $T=0.158^{* *}, \mathbf{R P}=0.158^{* *}, \mathbf{T} \times \mathbf{R P}$ $=0.315^{* *} ;$ endo-1,4- $\beta$-D glucanase $: \mathrm{T}=0.22^{*} * \mathrm{RP}=0.22 * *, \mathrm{~T} \times \mathbf{R P}=0.441^{* *}$; endopolygalacturonase: $\mathbf{T}=0.291 * *, \mathbf{R P}=0.291 * *, \mathbf{T} \times \mathbf{R P}=0.652$; exo-polygalacturonase: $\mathbf{T}=$ $2.302 * *, \mathbf{R P}=2.302 * *, \mathbf{T} \times \mathbf{R P}=4.604 * *$

Soluble solid contents (SSC), titratable acidity (TA) and SSC:TA ratio

During ripening, an increasing trend for SSC was observed in peach fruit, irrespective to treatments (Fig. 4A). Postharvest dips of SA significantly lowered peach fruit SSC, as compared to untreated fruit. Both SA-treated and untreated fruit exhibited decreased TA during ripening (Fig. 4B). However, application of SA significantly retained higher TA, as compared to untreated fruit. Average over the ripening period, peach fruit treated with $6 \mathrm{mM}$ SA exhibited about 1.38fold higher TA, as compared to untreated fruit. Peach fruit treated with SA and untreated fruit exhibited an increasing SSC: TA ratio during ripening (Fig. 4C). Postharvest application of SA significantly lowered SSC: TA ratio in peach fruit in contrast to untreated fruit during ripening 
(Fig. 4C). On day-4 of fruit ripening, fruit treated with $6 \mathrm{~m} M \mathrm{SA}$ exhibited the least value of SSC:TA ratio (about 1.7-fold) than untreated fruit.

\section{Ascorbic acid contents, total phenolic contents (TPC) and antioxidant scavenging activity (ASA)}

A significant decreased ascorbic acid contents were exhibited by both SA-treated and untreated fruit during ripening (Fig. 5A). However, application of different concentrations of SA retained higher amounts of ascorbic acid contents, as compared to untreated fruit. Fruit treated with higher concentration of SA revealed higher ascorbic acid contents compared with other treatments. On day-4 of fruit ripening, the highest ascorbic acid contents were observed in peach fruit treated with $6 \mathrm{~m} M \mathrm{SA}$, about 1.5-fold higher than untreated fruit. Postharvest application of different SA concentrations significantly enhanced the TPC in peach fruit compared with untreated fruit during ripening (Fig. 5B). About 1.36fold higher TPC were observed in $6 \mathrm{~m} M \mathrm{SA}-$ treated fruit, as compared to untreated peach fruit on day-4 of ripening. Irrespective to treatments, peach fruit showed an increased ASA during ripening (Fig. 5C). The ASA was significantly increased by the postharvest dips of SA as compared to untreated fruit. Increase in ASA was more pronounced in fruit treated with higher concentration of SA as compared to other treatments. Peach fruit treated with $6 \mathrm{mMSA}$ showed the highest ASA on day-4 of ripening, about 1.64-fold, higher than untreated fruits.

\section{Activities of catalase (CAT), peroxidase (POD) and superoxide dismutase (SOD) enzymes}

With progression of ripening, a gradual increasing trend for activity of CAT enzyme was observed in both SA-treated and untreated peach fruit (Fig. 6A). Activity of CAT enzyme significantly enhanced by postharvest application of SA in peach fruit, as compared to untreated fruit. This increase was more evident in fruit treated with higher concentration of SA than other treatments. The highest CAT activity was exhibited by peach fruit treated with $6 \mathrm{~m} M \mathrm{SA}$, about 1.42fold higher than untreated fruit on day-4 of ripening. An increasing trend of POD enzyme activity was observed in both SAtreated and untreated peach fruit during ripening (Fig. 6B). Postharvest application of SA significantly enhanced the activity of POD enzyme than control fruit. On day-4 of fruit ripening, maximum POD activity was observed in peach fruit treated with $6 \mathrm{mM} \mathrm{SA}$ about 1.32-fold higher than untreated fruit. Similarly, SA-treated and untreated fruit revealed significantly increased activity of SOD enzyme during ripening (Fig. 6C). Peach fruit treated with SA showed significant higher activity of SOD enzyme, as compared to untreated fruit. This increase was more pronounced in peach fruit reated with higher concentration of SA, as compared to other concentrations. Peach fruit treated with $6 \mathrm{~m} M \mathrm{SA}$ showed the highest activity of SOD, about 1.85 -fold higher than untreated fruit.

Relationship between fruit firmness, ethylene production, activities of fruit softening and antioxidative enzymes

During ripening at ambient conditions, fruit firmness of SA-treated peach fruit showed a significant $(P \leq 0.05)$ negative correlation with the activities of PE $(r=-0.58)$, EGase $(r$ $=-0.74)$, endo-PG $(r=-0.81)$ and exo-PG $(r$ $=-0.87$ ) enzymes (Table 1$)$. During ripening, ethylene production showed significant $(P \leq$ $0.05)$ positive correlation with activities of $\mathrm{PE}(r=0.38)$, EGase $(r=-0.42)$, endo-PG $(r$ $=-0.54)$ and exo-PG $(r=-0.41)$ enzymes. Activities of fruit softening enzymes showed significant $(P \leq 0.05)$ positive relation with TPC, ASA, activities of CAT, POD and SOD during ripening. 


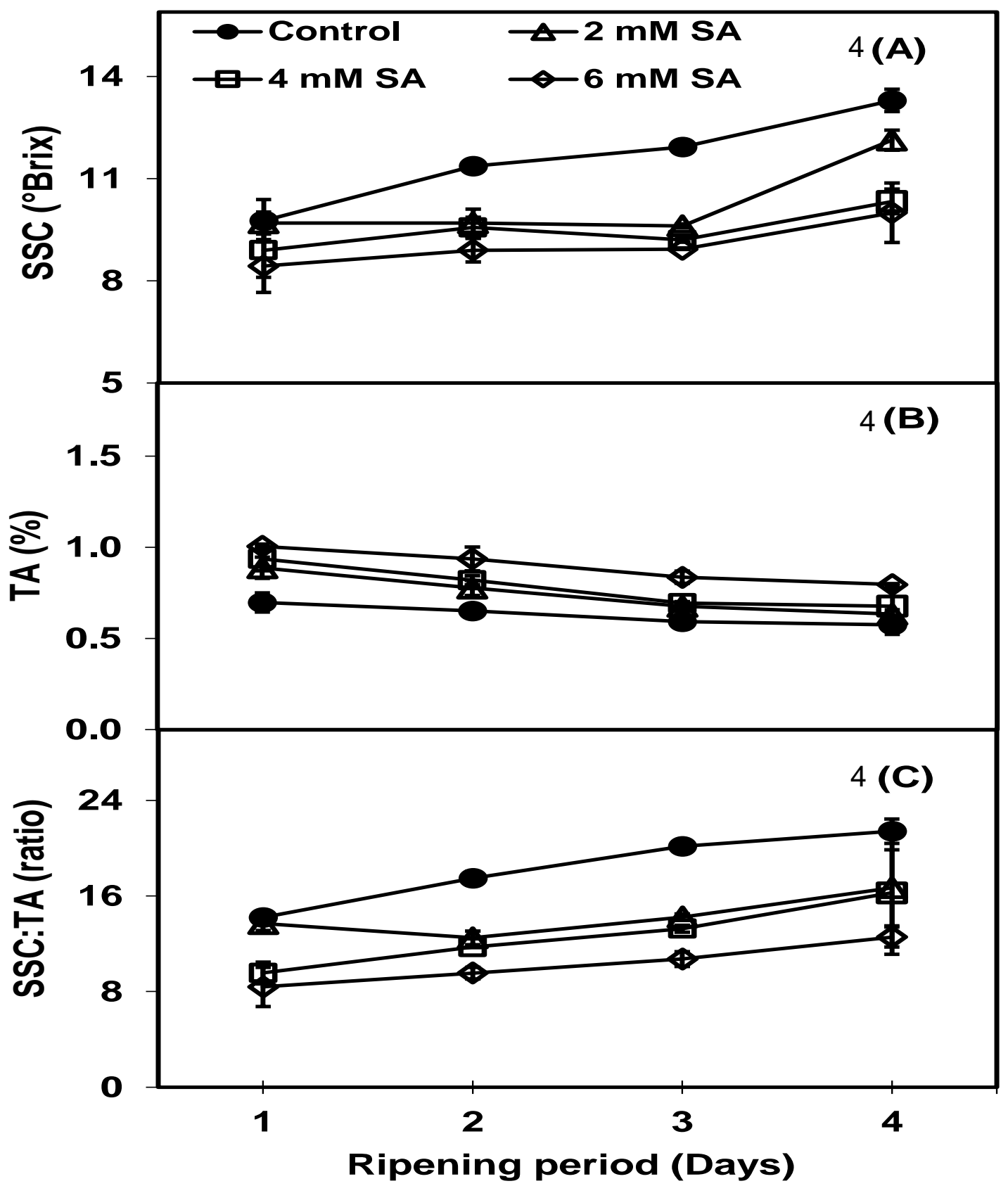

Figure 4. Effect of exogenous application of salicylic acid (T) on SSC (A), TA (B) and SSC:TA ratio (C) of 'Flordaking' peach fruit during ripening (RP). Vertical bars denotes SE of means. $\mathrm{n}=3$, LSD values (NS, *,** indicates non-significant, significant at $P \leq 0.05$ and significant at $P \leq 0.01$, respectively). soluble solid contents $(\mathrm{SSC}): \mathbf{T}=\mathbf{0 . 5 7 9 * *}, \mathbf{R P}=\mathbf{0 . 5 7 9} * *$, $\mathrm{T} \times \mathrm{RP}=\mathrm{NS}$; titratable acidity $(\mathrm{TA}): \mathrm{T}=0.043 * *, \mathrm{RP}=0.043 * *, \mathrm{~T} \times \mathrm{RP}=\mathrm{NS}$; SSC:TA ratio : $\mathbf{T}=1.22 * *, \mathbf{R P}=1.22 * *, \mathrm{~T} \times \mathbf{R P}=2.44 * *$ 


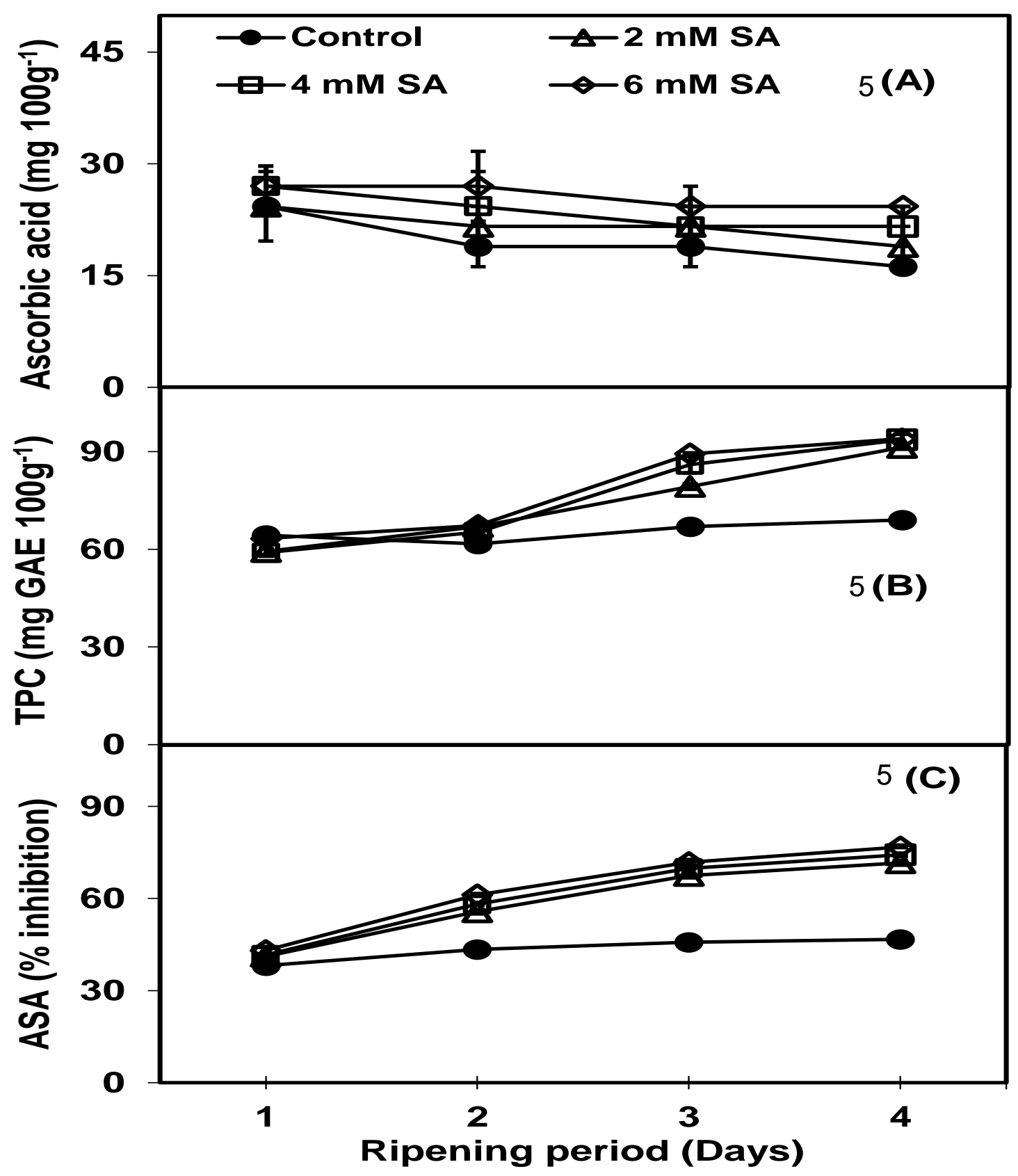

Figure 5. Effect of exogenous application of salicylic acid (T) on ascorbic acid (A), TPC (B) and ASA (C) in pulp tissues of 'Flordaking' peach during ripening (RP). Vertical bars denotes SE of means. $n=3$, LSD values $(\mathrm{NS}, * * *$ indicates non-significant, significant at $\mathbf{P}$ $\leq 0.05$ and significant at $P \leq 0.01$, respectively). Ascorbic acid: treatment $(T)=2.469 * *$, ripening period $(\mathrm{RP})=2.469 * \%, \mathrm{~T} \times \mathrm{RP}=4.938 * *$; total phenolic contents $(\mathrm{TPC}): \mathrm{T}=$ 4.932**, $R P=4.932 * *, T \times R P=11.029 *$; antioxidant scavenging activity $(\mathrm{ASA}): \mathrm{T}=\mathbf{2 . 4 6 9} * *$, $\mathrm{RP}=2.469 * *, \mathrm{~T} \times \mathrm{RP}=4.938 * *$ 


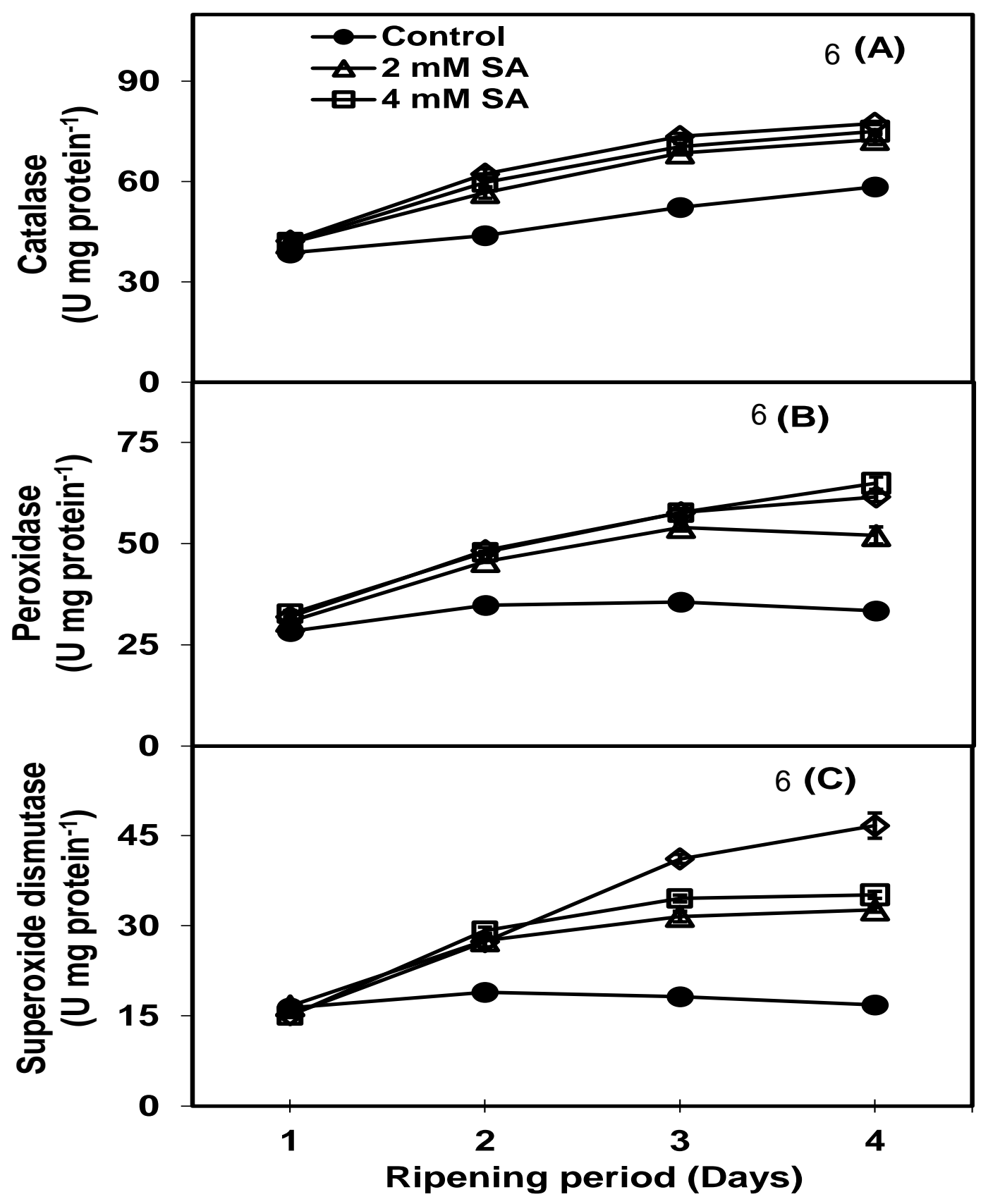

Figure 6. Effect of exogenous application of salicylic acid (T) on activity of catalase (A), peroxidase (B) and superoxide dismutase (C) enzymes in pulp tissues of 'Flordaking' peach during ripening (RP). Vertical bars denotes SE of means. $n=3$, LSD values (NS, *, ** indicates non-significant, significant at $P \leq 0.05$ and significant at $P \leq 0.01$, respectively). Catalase: $T=2.453 * *, R P=2.435 * *, T \times R P=4.905 * *$; peroxidase: $T=2.453 * *, R P=$ $2.453 * *, T \times R P=4.905 * *$; superoxide dismutase: $\mathbf{T}=2.564 * *, \mathbf{R P}=2.564 * *, T \times \mathbf{R P}=$ $5.128 * *$ 
Table 1. Relationship of fruit firmness and ethylene production with the activities of fruit softening and antioxidative enzymes in SA-treated peach fruit during ripening

\begin{tabular}{|c|c|c|c|c|}
\hline Parameters & PE & EGase & Endo-PG & Exo-PG \\
\hline Fruit firmness & $-0.585^{*}$ & $-0.746^{*}$ & $-0.812^{*}$ & $-0.871^{*}$ \\
\hline Ethylene production & $0.381^{*}$ & $0.417^{*}$ & $0.544^{*}$ & $0.411^{*}$ \\
\hline TPC & $0.459^{*}$ & $0.618^{*}$ & $0.675^{*}$ & $0.781^{*}$ \\
\hline ASA & $0.454^{*}$ & $0.542^{*}$ & $0.644^{*}$ & $0.753^{*}$ \\
\hline CAT & $0.458^{*}$ & $0.545^{*}$ & $0.641^{*}$ & $0.753^{*}$ \\
\hline POD & $0.384^{*}$ & $0.484^{*}$ & $0.528^{*}$ & $0.715^{*}$ \\
\hline SOD & $0.290^{\mathrm{NS}}$ & $0.346^{*}$ & $0.484^{*}$ & $0.596^{*}$ \\
\hline
\end{tabular}

*, NS are significant and non-significant at $P \leq 0.05$, respectively. $\mathrm{PE}=\mathrm{Pectin}$ esterase, EGase $=e n d o-1-4-\beta-\mathrm{Glucanase}$, endo $-\mathrm{PG}=$ endo polygalacturonase, exo $-\mathrm{PG}=$ exopolygalacturonase, $\mathrm{TPC}=$ total phenolic contents, $\mathrm{ASA}=$ antioxidant scavenging activity, $\mathrm{CAT}=$ catalase, $\mathrm{POD}=$ peroxidase, $\mathrm{SOD}=$ superoxide dismutase

\section{Discussion}

The results of the study suggest that postharvest SA application delays the peach fruit ripening by reducing ethylene production and respiration rate during fruit ripening, at ambient conditions. Based on these observations SA may be considered as antagonist of ethylene. Earlier, application of SA has also been reported to inhibit ethylene production during ripening of banana fruit [9]. Moreover, it has been reported that endogenous ethylene production is directly associated with activities of ethylene biosynthetic enzymes i.e. activities of 1aminocyclopropane-1-carboxylic acid synthase (ACS) and 1-aminocyclopropane-1carboxylic acid oxidase (ACO) enzymes [29]. Application of SA has been reported to reduce ethylene production by decreasing the activities of ACS and ACO enzymes of kiwifruit [30]. So, reduced ethylene production in SA-treated peach can be ascribed to reduced activities of ACS and ACO enzymes resulting in reduced ethylene biosynthesis. Similarly, application of SA resulted in lower activities of ACS and ACO enzymes and decreased ethylene production during fruit ripening has been observed in banana [9] and kiwifruit [31]. Likewise, increased respiration rate during peach fruit ripening, was found to be delayed by SA in a concentration dependent manner. It can be attributed to delayed fruit ripening by SA application. Moreover, during ripening a concomitant increase in respiration rate along with ethylene production is typical characteristics of climacteric fruit. SAtreated fruit exhibited reduced ethylene production which might have reduced the respiration rate of peach fruit. Previously, exogenous application of SA had been reported to decrease respiration rate of banana fruit during ripening [9].

Application of SA significantly decreased peach fruit weight loss during fruit ripening. Fruit weight loss during ripening results from water loss through respiration [32]. Reduction in fruit weight loss is ascribed to reduced respiration rate in SA-treated peach fruit. Similarly, [33] reduction in fruit weight loss has been reported in SA-treated banana and mandarin fruit $[9,34]$. SA-treated peach fruit showed reduced colour development, as compared to untreated fruit. Development of yellow colour in peach fruit during ripening is due to the disappearance of chlorophyll augmented by synthesis of carotenoids with progression of ripening [35]. Reduced colour development in SA-treated fruit could be due to reduced disappearance of chlorophyll contents. Tareen et al. [12] also found reduced colour development in SA-treated peach fruit during low temperature storage. Similarly, postharvest application of methyl 
salicylate significantly inhibited colour development in tomato. Fruit softening was significantly reduced by postharvest application of SA in peach fruit. It might be due to reduced activities of fruit softening enzymes in peach fruit by SA application. Because, according to our results, a significant negative correlation was found between activities of fruit softening enzymes and fruit firmness in SA-treated peach fruit (Table 1). Postharvest application of SA has been reported to reduce softening by reducing fruit softening enzymes in kiwifruit [36].

Peach fruit ripening at ambient accompanied with increased activities of PE, EGase, endoPG and exo-PG enzymes. However, application of SA reduced the activities of fruit softening enzymes including in a concentration dependent manner. Further, a significant positive correlations were found between ethylene production and activities of fruit softening enzymes at ripening in peach fruit. These results suggest that SA delays the fruit ripening. Previously, activities of exoPG and endo-PG enzymes had been found to be increased with progression of peach fruit ripening [37]. As previously discussed that SA-treated fruit exhibited reduced ethylene production, so reduced activities of fruit softening enzymes (PE, EGase, endo-PG and exo-PG) during post-storage ripening of peach fruit can be ascribed to reduced ethylene production in SA-treated fruit. Similar results had been observed in banana fruit and kiwifruit, where SA-treated fruit exhibited reduced activities of cell wall cell wall degrading enzymes $[9,31]$.

Application of SA in peach fruit significantly reduced the SSC of peach during ripening. SSC and soluble sugars may increase due to increased activities of sucrose biosynthesis enzymes viz. sucrose phosphate synthase (SPS) during fruit ripening [38]. This enzyme is activated by ethylene and the ripening process itself during storage [39]. Therefore, reduced SSC in SA-treated fruit might be due to lower activities of SPS enzymes than untreated fruit. Similarly, it has also been reported earlier that increased activity of SPS enzyme is responsible for rapid ripening process in banana fruit [40]. Similarly, lower SSC in MeSA-treated kiwifruit has been reported [36].

Postharvest application of SA showed an increased levels of ascorbic acid in treated peach fruit, as compared to untreated fruit during ripening. Certain bioactive compounds including ascorbic acid contribute to the antioxidant capacity of fruit [41]. Application of SA has been found to enhance antioxidant capacity of plant cells thus ascorbic acid being an antioxidant significantly boosted in SA-treated fruit. The findings of Kazemi et al. [42] supports our results where an increased levels of ascorbic acid was reported by the application of SA during storage of apple. TPC showed an increasing trend throughout the ripening period. SA being an important phenolic constituent contributes to the fruit defense system and also helps in biosynthesis of bioactive compounds including phenolics [43]. Similar results had been reported in two cultivars of sweet cherry during storage where a continuous increase in total phenolic contents were observed in SA, acetyl SA or oxalic acid-treated fruit than untreated fruit [44]. Antioxidant potential of cells is very important to reduce deterioration of fruit quality and senescence during low temperature storage [45]. Increased antioxidant scavenging activity (ASA) was observed throughout the ripening in SAtreated peach fruit. SA-treated peach exhibited a linear increase in ASA with proportion to SA concentration. It has been reported that SA, being a natural antioxidant, triggers the production of ROS scavenging genes thus enhances the antioxidant capacity of the cells [46]. So, SA-treated fruit exhibited increased ASA possibly due to SA 
potential to act as natural antioxidant. Similarly, application of SA increased antioxidant scavenging activity during storage in SA-treated peach fruit [12]. Application of SA increased the activities of antioxidative enzymes (CAT, POD and SOD) in peach during fruit ripening. Postharvest oxidative stress is characterized with increased ROS production, which causes fruit quality deterioration during storage. The defense against oxidative stress consist of activation of ROS scavenging enzymes like SOD and CAT [47]. It has been reported that salicylates activate free radical avoidance system as well as ROS scavenging system by enhancing the activities of antioxidative enzymes (SOD and CAT) in chilling atmosphere thus preventing postharvest oxidative stress [46]. Similar results had been reported in peach and sweet cherry fruit during storage by the application of SA; where, application of SA stimulated activities of CAT, SOD and POD enzymes $[12,48]$.

\section{Conclusion}

Postharvest treatment of SA reduced ethylene productions, fruit softening, activities of fruit softening enzymes (PE, EGase, endo-PG and exo-PG), with higher activities of antioxidative enzymes (CAT, POD and SOD) in peach fruit. Hence, postharvest application of $6 \mathrm{mMSA}$ can be used to reduce fruit softening and maintained better quality of 'Flordaking' peach fruit during ripening at ambient conditions.

\section{Authors' contributions}

Conceived and designed the experiments: AS Khan \& AU Malik, Performed the experiments: S Ullah \& K Razzaq, Analyzed the data: S Ullah, G Akhtar \& HN Faried, Contributed reagents/ materials/ analysis tools: S Ullah, K Razzaq \& AS Khan, Wrote the paper: S Ullah, M Amin \& K Razzaq.

\section{Acknowledgements}

The corresponding author gratefully acknowledges Higher Education
Commission, Pakistan for the grant of Indigenous PhD Fellowship (5000 Batch IV) during the course of $\mathrm{PhD}$ study.

\section{References}

1. FAOSTAT (2018).

http://faostat.fao.org/site/567/Desktop

Default.aspx ?PageID = 567\#ancor (Retrieved on $24^{\text {th }}$ June, 2018).

2. Ortiz A, Graell J, Lopez ML, Echeverria G \& Lara I (2010). Volatile ester-synthesising capacity in 'Tardibelle' peach fruit in response to controlled atmosphere and 1MCP treatment. Food Chem 123: 698-704.

3. Brummell DA, Dal-Cin V, Crisosto $\mathrm{CH} \&$ Labavitch JM (2004). Cell wall metabolism during the development of chilling injury in cold-stored peach fruit: association of mealiness with arrested disassembly of cell wall pectins. J Exp Bot 55: 2041-2052.

4. Pressey R \& Avants JK (1978). Difference in polygalacturonase composition of clingstone and freestone peaches. $J$ Food Sci 43: 1415-1417.

5. Zheng X, Tian S, Meng X \& Li B (2007). Physiological and biochemical responses in peach fruit to oxalic acid treatment during storage at room temperature. Food Chem 104: 156.

6. Macarisin D, Droby S, Bauchan G \& Wisniewski M (2010). Superoxide anion and hydrogen peroxide in the yeast antagonist fruit interaction: a new role for reactive oxygen species in postharvest biocontrol. Postharvest Biol Technol 58: 194-202.

7. Sun J, Li C, Nagendra-Prasad K, You X, Li L, Liao F, Peng H, He X, Li Z \& Zhang Y (2012). Membrane deterioration enzymatic browning and oxidative stress in fresh fruits of three litchi cultivars during six-day storage. Sci Hortic 148: 97-103.

8. Hayat S, Ali B \& Ahmad A (2007). Salicylic acid: biosynthesis, metabolismand physiological role in plants. pp 1-14. In: S. Hayat and A. Ahmad, (eds). Salicylic acid:a plant hormone. Springer, Dordrecht, (Netherlands).

9. Srivastava MK \& Dwivedi UN (2000). Delayed ripening of banana fruit by salicylic acid. Plant Sci 158: 87-96. 
10. Shafiee M, Taghavi TS \& Babalar M (2010). Addition of salicylic acid to nutrient solution combined with postharvest treatments (hot water, salicylic acid, and calcium dipping) improved postharvest fruit quality of strawberry. Sci Hortic 124: 40-45.

11. Al-Qurashi, AD \& Awad MA (2012). Postharvest salicylic acid treatment reduces chilling injury of 'Taify' cactus pear fruit during cold storage. J Food Agric Environ 10: 120-124.

12. Tareen MJ, NA Abbasi \& Hafiz IA (2012). Postharvest application of salicylic acid enhanced antioxidant enzyme activity and maintained quality of peach cv. 'Flordaking' fruit during storage. Sci Hortic 142: 221228.

13. Rao TVR, NB Gol \& Shah KK (2011). Effect of postharvest treatments and storage temperatures on the quality and shelf life of sweet pepper (Capsicum annum L.). Sci Hortic 132: 18-26.

14. Leslie CA \& Romani RJ (1988). Inhibition of ethylene biosynthesis by salicylic acid. Plant Physiol 88: 833-837.

15. Al-Qurashi, AD \& Awad MA (2012). Postharvest salicylic acid treatment reduces chilling injury of 'Taify' cactus pear fruit during cold storage. J Food Agric Environ 10:120-124.

16. Bal E \& Celik S (2010). The effects of postharvest treatments of salicylic acid and potassium permanganate on the storage of kiwifruit. Bulgarian J Agric Sci 16: 576-584.

17. Babalar M, Asghari M, Talaei A \& Khosroshahi A (2007). Effect of pre- and postharvest salicylic on ethylene production, fungal decay acid treatment and overall quality of 'Selva' strawberry fruit. Food Chem 105: 449-453.

18. Khademi O, Zamani Z, Mostofi Y, Kalantari S \& Ahmadi A (2012). Extending storability of persimmon fruit cv. Karaj by postharvest application of salicylic acid. Agric Sci Technol 14: 1067-1074

19. Krishna H, Das B, Attri BL, Kumar A \& Ahmed N (2012). Interaction between different pre- and postharvest treatments on shelf life extension of 'Oregon Spur' apple. Fruits 67: 31-40.
20. Qin, GZ, Tian SP, Xu Y \& Wan YK (2003). Enhancement of biocontrol efficacy of antagonistic yeasts by salicylic acid in sweet cherry fruit. Physiol. Mol Plant Pathol 62: 147-154.

21. Zhang HY, Ma LC, Wang L, Jiang S, Dong Y \& Zheng XD (2008). Biocontrol of gray mold decay in peach fruit by integration of antagonistic yeast with salicylic acid and their effects on postharvest quality parameters. Biological Control 47: 60-65.

22. Panahirad S, Zaare-Nahandi F, Safaralizadeh R \& Alizadeh-Salteh S (2012). Postharvestcontrol of Rhizopus stolonifer in peach (Prunus Persica L. Batsch) fruits using salicylic acid. J Food Safety 32: 502-507.

23. Ding ZS, Tian SP, Zheng XL, Zhou ZW \& $\mathrm{Xu}$ Y (2007). Responses of reactive oxygen metabolism and quality in mango fruit to exogenous oxalic acid or salicylic acid under chilling temperature stress. Physiol Plantarum 130: 112-121.

24. Wang L, Chen S, Kong W, Li S \& Archbold DD (2006). Salicylic acid pretreatment alleviates chilling injury and affects the antioxidant system and heat shock proteins of peaches during cold storage. Postharvest Biol Technol 41: 244-251.

25. Cai C, Li X \& Chen KS (2006). Acetylsalicylic acid alleviates chilling injury of postharvest loquat (Eriobotrya japonica Lindl.) fruit. European Food Res Technol 223: 533-539.

26. Sayyari M, Castillo S, Valero D, Diaz-Mula HM \& Serrano M (2011). Acetyl salicylic acid alleviates chilling injury and maintains nutritive and bioactive compounds and antioxidant activity during postharvest storage of pomegranates. Postharvest Biol Technol 60: 136-142.

27. Yang ZF, Cao SF, Zheng YH \& Jiang YM (2012). Combined salicyclic acid and ultrasound treatments for reducing the chilling injury on peach fruit. J Agric Food Chem 60: 1209-1212.

28. Ullah S, Khan AS, Malik AU \& Shahid M (2013). Cultivar and harvest location influence fruit softening and antioxidative activities of peach during ripening. Int $J$ Agric Biol 15: 1059-1066. 
29. Khan AS \& Singh Z (2007). 1-MCP regulates ethylene biosynthesis and fruit softeningduring ripening of 'Tegan Blue' plum. Postharvest Biol Technol 43: 298306.

30. Khan AS \& Singh Z (2008). 1Methylcyclopropene application and modified atmosphere packaging affect ethylene biosynthesis, fruit softening, and quality of 'Tegan blue' Japanese plum during cold storage. J Am Soc Hortic Sci 133(2): 290-299.

31. Zhang, Y, Chen KS, Zhang SL \& Ferguson I (2003). The role of salicylic acid in postharvest ripening of kiwifruit. Postharvest Biol Technol 28: 67-74.

32. Cutting, JGM \& Wolstenholme BN (1991). Maturity effects on avocado postharvest physiology in fruits produced under cool environmental conditions. South African Avocado Growers' Assoc Yearbook 14: 2426.

33. Ding CK \& Wang CY (2003). The dual effects of methyl salicylate on ripening and expression of ethylene biosynthetic genes in tomato fruit. Plant Sci 164: 589-596.

34. Zheng Y \& Zhang Q (2004). Effects of polyamines and salicylic acid postharvest storage of 'Ponkan' mandarin. Acta Hortic 632: 317-320.

35. Lill RE, O'Donegue EM \& King GA (1989). Postharvest physiology of peaches and nectarines. Hortic Rev 11: 413-452.

36. Aghdam, MS, Motallebiazar A, Mostofi Y, Moghaddam JF \& Ghasemnezhad M (2010). Effects of MeSA vapor treatment on the postharvest quality of 'Hayward' kiwifruit. Acta Hortic 877: 743-748.

37. Ghiani A, Onelli E, Aina R, Cocucci M \& Citterio S (2011). A comparative study of melting and non-melting flesh peach cultivars reveals that during fruit ripening endopolygalacturonase (endo-PG) is mainly involved in pericarp textural changes, not in firmness reduction. $J$ Exp Bot 62: 40434054.

38. Hubbard NL, Pharr DM \& Huber SC (1991). Sucrose phosphate synthase and other sucrose metabolizing enzymes in fruits of various species. Plant Physiol 82: 191-196.
39. Langenkamper G, McHale R, Gardner RC \& MacRae E (1998). Sucrose phosphate synthase steady-state mRNA increases in ripening kiwifruit. Plant Mol Biol 36: 857869.

40. Cordenunsi RR \& Lajolo FM (1995). Starch breakdown during banana ripening. Sucrose synthase and sucrose phosphate synthase. $J$ Agric Food Chem 43:347-351

41. Serrano M, Giullen F \& Martinez-Romero D (2005). Chemical constituents and antioxidant activity of sweet cherry at different ripening stages. J Food Agric Food Chem 53: 2741-2745.

42. Kazemi M, Aran M \& Zamani S (2011). Effect of salicylic acid treatments on quality characteristics of apple fruits during storage. Am J Plant Physiol 6: 113-119.

43. Huang R, Xia R, Lu Y, Hul L \& Xu Y (2008). Effect of pre-harvest salicylic acid spray treatment on post-harvest antioxidant in the pulp and peel of 'Cara Cara' navel orange (Citrus sinenisis L. Osbeck). J Sci Food Agric 88: 229-236.

44. Valero D, Diaz-Mula HM, Zapata PJ, Castillo S, Guillen F, Martinez-Romero D \& M. Serrano M (2011). Postharvest treatments with salicylic acid, acetylsalicylic acid or oxalic acid delayed ripening and enhanced bioactive compounds and antioxidant capacity in sweet cherry. J Agric Food Chem 59: 5483-5489.

45. Lurie S (2003). Antioxidants: Postharvest Oxidative Stress in Horticultural Crops. pp. 131-150. Foods Products Press. The Howerth Press, Binghampton, NY.

46. Asghari M \& Aghdam MS (2010). Impact of salicylic acid on post-harvest physiology of horticultural crops. Trends Food Sci Technol 21: 502-509.

47. Buchanan BB, Gruissem W \& Jones RL (2000). Biochemistry and molecular biology of plants. American Society of Plant Physiologists. Maryland (USA).

48. Chan ZL \& Tian SP (2006). Induction of $\mathrm{H} 2 \mathrm{O} 2$-metabolizing enzymes and total proteinsynthesis by antagonistic yeast and salicylic acid in harvested sweet cherry fruit. Postharvest Biol Technol 39: 314-320. 